\title{
A morbillivirus causing mass mortality in seals
}

\begin{abstract}
During an outbreak of a serious apparently infectious disease among harbour seals (Phoca vitulina), which started in the Kattegat area in April 1988 and rapidly spread to the North sea, the Wadden sea and the Baltic sea, $>17000$ animals died within a period of eight months. In August 1988 it was realized that the clinical symptoms and pathological lesions were similar to those found in canine distemper': apart from general depression and fever, the animals suffered from severe respiratory, gastrointestinal and central nervous disease and a variety of viral, bacterial and parasitic infections were frequently encountered, suggesting a severe malfunctioning of the immune system. At different expert meetings, held in several of the countries involved, possible explanations for the deaths were not only attributed to an infectious agent, but also to effects of overpopulation and environmental pollution. Seroepizootiological studies and the failure of vaccination experiments suggested that a herpesvirus and a picornavirus, which had been isolated from dead seals at the beginning of the outbreak ${ }^{2}$, were opportunistic infections occurring in animals suffering from another infection ${ }^{1}$ rather than being the primary cause of the outbreaks. Serological studies were then extended to other viruses of carnivores, known to cause similar symptoms. Screening of a large panel of seal sera from The Netherlands, Denmark, FRG, Sweden and the UK, collected before and during the outbreak, in a virus neutralization test for the presence of canine distemper virus (CDV) neutralizing antibodies, indicated that $C D V$ or a closely related morbillivirus was the primary cause of the disease outbreak ${ }^{1}$. The initial failure to isolate the virus from organs of affected animals may be explained by the fact that no isolation procedures were used which favour the isolation of morbilliviruses ${ }^{3}$. We isolated the virus directly in cell cultures and after passage through SPF dogs, which developed $C D V$-neutralizing antibodies and mild clinical signs suggestive of $C D V$ infection. The presence of morbillivirus in infected cells was shown by immunofluorescence with $C D V$-specific antibodies showing syncytia formation and by negative contrast electron microscopy ${ }^{4}$.
\end{abstract}

To study further where and when the morbillivirus infection had been introduced into the seal populations, the serological studies were extended to samples collected in other areas of the world between 1984 and 1988. All samples proved to be negative in the CDV-neutralization assay. As the humoral immune response after natural morbillivirus infection persists for several years and perhaps even for life - as, for example, in the dog after CDV infection - and assuming that this also holds true for the morbillivirus infection of seals, we concluded that the morbillivirus involved in the outbreak does not commonly infect pinnipeds ${ }^{1,4}$. The first confirmation of our findings came from the work of Kennedy et al., who also demonstrated the presence of morbillivirus antigen in organs of infected harbour seals and isolated the virus from organs of an affected seal ${ }^{5}$.

Further evidence for a morbillivirus as the primary cause of the outbreak came from the work by Mahy et al., who showed by nucleic acid hybridization studies, that the virus was similar to both CDV and rinderpest virus (RPV), but should probably be considered a new member of the genus Morbillivirus ${ }^{6}$. This could also be concluded from the results obtained by Cosby et al. with a panel of monoclonal antibodies, raised against $\mathrm{CDV}$ or $\mathrm{RPV}^{7}$. Final proof that the primary cause of the outbreak was indeed the newly identified morbillivirus, now christened phocid distemper virus (PDV), came from the evaluation of the efficacy of two inactivated CDV vaccines in protecting seals against experimental PDV infection ${ }^{8}$. Indeed we showed that seronegative seals were protected from fatal challenge with organ material from dead seals, by vaccination with these vaccines. This experiment not only provided final proof for the causative role of the morbillivirus for the outbreak, by fulfilling the last of Koch's postulates, but also provided a useful tool to protect seals in sanctuaries and other places where seals are kept in captivity.

The origin of PDV is not known at present. In a recent serological study among seals in Greenland, it was shown that morbillivirus-specific antibodies were present in these seals before the beginning of the outbreak in the seals of north-western Europe ${ }^{9}$. In collaboration with a Siberian group, we recently demonstrated the presence of CDV-neutralizing antibodies in the sera of Lake Baikal seals (Phoca sibirica), during and after an outbreak of a distemper-like disease, that occurred in the year before the outbreak in north-western Europe $^{10,11}$. The virus was isolated and further biological and molecular biological characterization of viruses isolated during both outbreaks are being conducted at present in order to conclude whether an epizootiological link is likely to have existed between both the outbreaks. Our recent finding that morbillivirusspecific antibodies, not neutralizing CDV, could be demonstrated with an enzyme-linked immunosorbent assay in sera from seals in north-western Europe before the outbreak took place, may reflect the existence of antigenically different morbilliviruses in the seals of north-western Europe ${ }^{12}$. The virus circulating in the recent outbreak is distinguished by having increased pathogenicity in harbour seals, which has enabled the identification of the seal distemper problem. It may not have been noticed had the virus only infected grey seals (Halichoerus gryphus), which show milder disease signs. The sudden appearance of a seal morbillivirus with altered biological properties could have been due to a mutation which altered the pathogenicity of a pre-existing non-pathogenic virus within the host species, or to a mutation that delayed the virus' host-species range.

Albert Osterhaus
Department of Immunobiology,
National Institute of Public Health
and Environmental Protection,
PO Box 1, 3720 BA Bilthoven,
The Netherlands




\section{References}

1 Osterhaus, A.D.M.E. and Vedder, E.J. Identification of virus causing recent seal deaths. Nature 1988, 335, 20

2 Osterhaus, A.D.M.E. Seal death. Nature 1988, 334, 301-302

3 Appel, M.J.G. Canine Distemper Virus. In Virus Infections of Vertebrates, Vol. 1: Virus Infection of Carnivores. Ed. Horzinek, M.C., Elsevier, Amsterdam, 1987, pp. 133161

4 Osterhaus, A., Groen, J., De Vries, P., UytdeHaag, F., Klingeborn, B. and Zarnke, R. Canine distemper virus in seals. Nature 1988, 335, 403

5 Kennedy, S.; Smyth, J.A., McCullough, S.J., Allan, G.M., McNeilly, F.M. and McQuaid, S. Confirmation of cause of recent seal deaths. Nature 1988, 335, 404

6 Mahy, B.W.J., Barrett, T., Evans, S. Anderson, E.C. and Bostock, C.J. Characterization of a seal morbillivirus. Nature 1988, 336, 115
7 Cosby, S.L., McQuaid, S., Duffy, N., Lyons, C., Rima, B.K., Allan, G.M. ot al. Characterization of a seal morbillivirus. Nature 1988, 336, 115-116

8 Osterhaus, A.D.M.E., UytdeHaag, F.G.C.M., Visser, I.K.G., Vedder, E.J., Reijnders P.J.M., Kuiper, J. and Brugge, H.N. Seal vaccination success. Nature 1988, 337, 21

9 Dietz, R. and Ansen, C.T. Clue to seal epizootic? Nature 1989, 338, 627

10 Grachev, M.A., Kumarev, V.P., Mamaev, L.V., Zorin, V.L., Baranova, L.V., Denikina, N.N. et al. Distemper virus in Baikal seals. Nature 1989, 338, 209

11 Osterhaus, A.D.M.E., Groen, J., UytdeHaag, F.G.C.M., Visser, I.K.G., Van de Bildt, M.W.G., Bergman, A. and Klingeborn, B. Distemper virus in Baikal seals. Nature 1989, 338, 209-210

12 Osterhaus, A.D.M.E., Groen, J., UytdeHaag, F.G.C.M., Visser, I.K.G., Vedder, E.J., Crowther, J. and Bostock, C.J. Morbilivirus infections in European seals before 1988. Vet. Rec. in press

\section{Prospects for the total eradication of rinderpest}

Rinderpest, a major economic problem of Africa and Asia, is a highly contagious viral disease of cattle and buffalo with $>90 \%$ mortality in susceptible herds. We have developed an effective vaccinia virus recombinant vaccine for rinderpest which protects cattle against challenge by more than 1000 times the lethal dose of the virus. The vaccine circumvents the major logistical problems of the Plowright tissue culture vaccine that occasioned previous failures to eradicate rinderpest by vaccination. The recombinant can easily be propagated and administered by scarification, using methods employed in the world-wide eradication of smallpox. More importantly, the lyophilized form of vaccinia virus is thermostable and does not require maintenance of the cold chain, a distinct advantage in the hot and arid regions of Africa and Asia.

Rinderpest is not only the single most important disease of livestock in developing countries of Africa and Asia, but has also played a crucial role in the development of the veterinary profession. Now rinderpest may enter a final chapter in its history as the focus of one of the first effective recombinant, vaccines to find general use. While it took nearly 200 years and a concerted international disease control campaign to eradicate smallpox using Jenner's vaccination technique, we could use vaccinia virus to rid the world of rinderpest within a decade. To eradicate rinderpest using a vaccinia virus recombinant vaccine will clearly demonstrate the potential of this new generation of vaccines in controlling the major infectious diseases that inflict economic hardship and suffering on humans and animals worldwide.

An acute, febrile, highly con- tagious viral disease of ruminants (particularly cattle and buffalo) with a rapid course and high mortality rate, rinderpest is characterized by inflammation, haemorrhaging, necrosis and erosion of the gastrointestinal tract accompanied by bloody diarrhoea, wasting and death. It was first recognized as a distinct disease during the great European epizootic of 376-386 AD, and in the 18 th century alone, rinderpest wiped out an estimated 200 million cattle in Europe ${ }^{1}$. Cattle from India introduced to Somalia in 1889 during the Italian invasion of Ethiopia kindled the most spectacular of recent epizootics. The disease quickly afflicted the entire cattle population of Ethiopia, the mortality rate exceeding $90 \%$. The year 1889 is commemorated on the Ethiopian calendar as 'Yekebit elkit', meaning 'the year of the annihilation of cattle'.
Shortly thereafter, the disease engulfed the entire continent of Africa, killing hundreds of millions of cattle.

The urgent need to combat rinderpest resulted in the establishment of the first veterinary school in Europe in 1762 and the convening of the First International Veterinary Congress at Hamburg in 1863. More recently, rinderpest was a major impetus for the founding of the Office Internationale des Epizooties in Paris ${ }^{1}$. In addition, the largest disease eradication programme in the history of veterinary medicine, the Joint Program $\backslash 15 \quad(\mathrm{JP} \backslash 15)$ to eradicate rinderpest, was initiated through the coordinated efforts of a number of governments and international organizations in 1962. During the execution of this programme, conducted in western Africa through 1968 , a total of 81484126 cattle were vaccinated occasioning a dramatic drop in the number, size and distribution of rinderpest outbreaks. After this successful campaign, the JP $\backslash 15$ programme was extended to six countries in eastern Africa (Kenya, Tanzania, Uganda, Somalia, Ethiopia and the Sudan). Within 3 years a total of 124099454 cattle were vaccinated in those countries ${ }^{2}$.

Because of failure to sustain surveillance, vaccination and control measures instituted during the JP $\backslash 15$ eradication programme, rinderpest is again rampant in Africa. Many of the reasons for recrudescence of rinderpest in Africa are related to problems in vaccine production, preservation and delivery. Developing countries do not have the technical resources to manufacture the Plowright tissue culture vaccine or to purchase this relatively expensive product from abroad. The arid, hot desert regions throughout much of Africa lack the reliable refrigeration facilities needed to keep tissue culture vaccine potent and efficacious. The continuous movement of nomadic herdsmen and their animals also makes it difficult to assemble cattle for vaccination. Many countries lack the financing to buy syringes and needles, distribute vaccine and monitor control measures. A vaccinia virus recombinant vaccine for rinderpest could overcome most of these drawbacks to traditional vaccine programmes in developing countries.

Elaborate and advanced molecular biology techniques and facilities have been used to construct a very effective rinderpest vaccinia virus recombinant 